\title{
GERMINAÇÃO E CRESCIMENTO INICIAL DE Machaerium brasiliense VOGEL (FABACEAE) EM CASA DE VEGETAÇÃO
}

\author{
Lindamir Hernandez Pastorin ${ }^{1}$, Mariza Barion Ro magnolo ${ }^{1}$, Caroline Barbeiro ${ }^{2}$, Renata Go mes de Oliveira \\ Guerre iro ${ }^{2}$, Priscila Marques da Costa ${ }^{2}$, Maria Aparecida Sert ${ }^{1}$, Luiz Antonio de Souza ${ }^{1}$ \\ ${ }^{1}$ Universidade Estadual de Maringá, Departamento de Biologia, Maringá, Paraná, Brasil - lindamirpastorini@yahoo.com.br; \\ mbromagnolo@gmail.com; masert@uem.br; lasouza@uem.br \\ ${ }^{2}$ Universidade Estadual de Maringá, Curso de Ciências Biológicas, Maringá,Paraná, Brasil - caroline-lila@ hotmail.com; \\ re_guerreiro_15@hotmail.com; priscila.mqs@hotmail.com
}

Recebido para publicação: 26/01/2015 - Aceito para publicação: 11/02/2016

\begin{abstract}
Resumo
Machaerium brasiliense Vogel é uma espécie arbórea, conhecida popularmente como pau-san gue, jacarandábico-de-pato e sapuva. Com o objetivo de verificar a germinação, sementes de $M$. brasiliense foram mantidas sob temperatura de $20^{\circ}, 25^{\circ}$ e $30^{\circ} \mathrm{C}$, em câmara de germinação com fotoperíodo de $12 \mathrm{~h}$ ou escuro contínuo. Para análise do crescimento inicial, avaliaram-se, aos 90, 180, 270 e 360 dias após o transplante (DAT), a altura, o comprimento da raiz, a massa seca da parte aérea, da raiz e total e o número de folhas de plantas mantidas em casa de vegetação. A presença ou ausência de luz não influenciou o desempenho das sementes, observando-se maior porcentagem de germinação (PG) para as sementes submetidas a 20 e $25{ }^{\circ} \mathrm{C}$, o mesmo sendo verificado para o parâmetro índice de velocidade de germinação (IVG). O menor tempo médio de germinação (TMG) foi observado a $30^{\circ} \mathrm{C}$. Em relação aos parâmetros de crescimento, os maiores valores foram obtidos aos 270 e 360 DAT, não ocorrendo diferença estatística entre esses dois períodos de av aliação. A presença de nódulos radiculares foi observada a partir dos 180 DAT.

Palavras-chave: Massa seca; nódulos; parte aérea; raiz; temperatura.
\end{abstract}

\begin{abstract}
Germination and initial growth of Machaerium brasiliense Vogel (Fabaceae) in a greenhouse. Machaerium brasiliense Vogel is an arboreal species. popularlv known as "pau-sangue". "iacarandá-bico-de-pato" and "sapuva" (State of Paraná, Brazil). A iming to analyze the germination, M. brasiliense seeds were kept at $20^{\circ}$, $25^{\circ}$ and $30^{\circ} \mathrm{C}$ in a growth chamber with a $12 \mathrm{~h}$ photoperiod or continuous darkness. For initial growth. plants were analyzed for height, len gth of root, shoot and root dry mass, total dry mass and the number of leaves at 90. 180. 270 and 360 davs after transplanting (DAT).The presence or absence of light showed no effect on the performance of seeds. with a higher germination percentage (PG) found for seeds at 20 and $25^{\circ} \mathrm{C}$. as verified for the germination speed index (IVG). The shortest average germination time (TMG) was observed at $30{ }^{\circ} \mathrm{C}$. Regarding the growth parameters. the highest values were obtained at 270 and 360 DAT. with no statistical difference between these two evaluation periods. The presence of root nodules was verified from 180 DAT.

Keywords: Dry mass; nodules; shoot; root; temperature.
\end{abstract}

\section{INTRODUÇÃO}

Fabaceae é considerada a maior família de plantas no Brasil, com 2.100 espécies e 188 gêneros, dos quais 31 são endêmicos, estando representad a em todos os biomas brasileiros (ANDRADE et al., 2009). Entre os gêneros de Fabaceae, Machaerium é predominantemente neotropical, com aproximadamente 130 espécies de árvores, arbustos e lianas, ocorrendo do sul do México ao norte da Argentina, sendo que no Brasil há cerca de 80 espécies (FILA RDI; LIMA, 2014).

Macherium brasiliense Vogel (Fabaceae - Faboidae), conhecida como pau-sangue, jacarandá, canelado-brejo ou sapuva, é uma espécie arbórea com cerca de 6-13 metros de altura, heliófila, característica de formações semideciduais, ocorrendo do Maranhão ao Paraná (LORENZI, 2014), sendo frequente nas formações florestais da bacia do Paraná.

Nos últimos anos, houve um aumento no número de pesquisas relacionadas à propagação de espécies florestais nativas, devido a problemas ambientais, como desmatamentos e queimadas, como também para a expansão agropecuária, atividades de mineração, construção de barragens, estradas e ferrovias (ANDRADE et al., 2003; OLIVEIRA et al., 2013). Por essa razão, a restauração dessas áreas vem sendo cada vez mais executada, devido à situação na qual se encontram os ecossistemas, sendo que a técnica de restauração de áreas degradadas através do plantio de mudas tem sido utilizada na maioria das situações (SILVA et al., 2015). 
De acordo com Vini e Rodrigues (2007), há u m déficit de sementes e consequentemente de produção de mudas de espécies nativas comalta diversidade para uso na recuperação de áreas degradadas.

Assim, pesquisas relacionadas à germinação e emergência das plântulas podem contribuir para o conhecimento da sua estratégia reprodutiva e regeneração, como também para a conservação e manejo das espécies (YANG et al., 2008). Além disso, as informações acerca da germinação e crescimento inicial podem contribuir também para a produção de mudas de qualidade a serem utilizadas em programas de restauração florestal.

A germinação constitui um conjunto de processos fisiológicos que se inicia na embebição e culmina na protusão da radícula, sendo a fase mais vulnerável e crucial na história de vida das plantas (FERREIRA; BORGHETTI, 2004).

Vários fatores podem influenciar a germinação, como a presença ou ausência de luz e a temperatura, sendo estes importantes para o recrutamento e estabelecimento de plântulas (SOCOLOWSKI; TAKA KI, 2007). A qualidade da luze a temperatura do solo são importantes reguladores da germinação de espécies pioneiras em ecossistemas de florestas tropicais (OROZCO-SEGOVIA et al., 1987).

Após a germinação, a formação de mudas mais vigorosas permite maior chance de sucesso no estabelecimento da planta, bem co mo maximiza seu crescimento ao diminuir o te mpo de trans plante para o campo. Isso pode ser alcançado observando-se parâmetros morfológicos ou realizando análises do crescimento em mudas (LIMA et al., 2008). A análise de crescimento se baseia fundamentalmente no fato de que cerca de $90 \%$, em média, da matéria seca acumulada pelas plantas ao longo do seu crescimento resulta da atividade fotossintética, avaliandose através de variações em tamanho de algum aspecto da planta (BENINCASA, 1988).

$\mathrm{O}$ estudo do desenvolvimento inicial de plantas e dos padrões de repartição de biomassa contribui para se entender o funcionamento das espécies em formações florestais. As variáveis de crescimento podem caracterizar os estádios de sucessão das espécies. Uma espécie climácica ou de sucessão tardia apresenta crescimento lento e geralmente tolerando a sombra, enquanto uma espécie pioneira apresenta maior altura, maior produção de folhas e maior crescimento em extensão do caule (PINZÓN-TORRES; SCHIA VINATO, 2008; RAMAKRISHNAN et al. 1982).

Vários estudos têm sido realizados sobre a germinação e o crescimento de espécies de Fabaceae nativas (SCHUMACHER et al., 2004; FERREIRA et al., 2012; MONDO et al., 2008; RODRIGUES et al., 2007), no entanto foram encontrados poucos registros considerando a germinação e o crescimento de M. brasiliense. Estudos sobre a época adequada para colheita das sementes e desempenho germinativo em câmara de germinação de $M$. brasiliense foram realizados por Guimarães e Barbosa (2007). Informações sobre o crescimento inicial dessa espécie são escassos, sendo que a avaliação do crescimento de mudas de M. brasiliense em áreas de dunas foi realizado por Araújo et al. (2014).

Considerando, que $M$. brasiliense é recomendada para a restauração de áreas degradadas (LORENZI, 2014), o presente trabalho teve por objetivo avaliar a germinação em condições de laboratório e o seu crescimento em casa de vegetação, vis ando dar subsídios à produção de mudas des sa espécie, levando em conta os as pectos da germinação e do crescimento inicial.

\section{MATERIAL E MÉTODOS}

\section{Coleta do material vegetal}

A coleta dos frutos de M. brasiliense ocorreu na Estação Ecológica de Caiuá, localizada em Diamante do Norte, Paraná, Brasil. A região tem clima Cfa, com média de temperatura anual entre 21 e $22{ }^{\circ} \mathrm{C}$ (IAPAR, 2012), e a vegetação encontra-se sob o domínio da Floresta Estacional Semidecidual (IBGE, 2012). Os frutos maduros foram coletados de 6 indivíduos diferentes, e as sementes foram obtidas manualmente.

\section{Bioensaios de germinação}

Os frutos foram levados ao laboratório de Fisiologia Vegetal da Universidade Estadual de Maringá, obtendo-se as sementes, que foram lavadas em água corrente por várias vezes, para eliminação de substâncias fenólicas presentes no tegumento, desinfestadas com hipoclorito de sódio comercial, na concentração de $1,25 \%$, por 20 minutos, e por último mantidas emágua destilada, com agitação manual, por 2 minutos (BRASIL, 2013).

Para os bioensaios de germinação, as sementes de M. brasiliense foram colocadas em placas de Petri, contendo dois discos de papel filtro, umedecidos com água destilada. As placas de Petri foram mantidas em câmara de germinação, sob fotoperíodo de $12 \mathrm{~h}$ e temperatura de 20,25 e $30^{\circ} \mathrm{C} \pm 1$. As sementes também foram submetidas ao escuro contínuo, sendo as placas de Petri envolvidas em alumínio, e a avaliação da germinação sob luz verde (MOTA; GARCIA, 2013).

A observação da germinação ocorreu em intervalos de $24 \mathrm{~h}$, sendo as sementes consideradas germinadas quando houve protusão da radícula. 
Foram utilizadas quatro repetições para cada temperatura, tanto nas condições de fotoperíodo 12 horas quanto de escuro contínuo, sendo que cada placa de Petri recebeu 25 sementes de M. brasiliense, totalizando 100 sementes em cada tratamento.

A germinação foi avaliada a partir da porcentagem de germinação (PG), do índice de velocidade de germinação (IVG) e do tempo médio de germinação (TMG), de acordo com Maguire (1962) e Ferreira e Borghetti (2004).

Os dados referentes a PG, IVG e TMG apresentaram normalidade e homogeneidade, sendo então submetidos a ANOVA e comparados pelo teste de Tukey ao nível de 5\% de probabilidade.

\section{Obtenção de plântulas e análise do crescimento}

O experimento para análise do crescimento foi realizado em casa de vegetação, entre os meses de setembro de 2012 e setembro de 2013.

Para obtenção das plântulas, sementes de M. brasiliense foram colocadas em bandeja de isopor contendo areia de média granulometria e substrato comercial orgânico Genesolo®, na proporção de 2:1, respectivamente.

Após a emergência e o aparecimento dos primeiros eófilos, as plântulas foram transferidas para sacos plásticos pretos, com dimensões de 18 x $25 \mathrm{~cm}$, contendo o mes mo substrato.

Aos 90, 180, 270 e 360 dias após o transplante (DAT), quatro plantas de cada tratamento foram avaliadas quanto ao número de folhas, altura da parte aérea, comprimento da raiz, massa seca da parte aérea, massa seca da raiz, massa seca total, razão massa seca da parte aérea/massa seca da raiz (MSPA/MSR) e ocorrência de nódulos. Para obtenção da matéria seca, o material vegetal foi colocado em estufa de secagem e esterilização a $60^{\circ} \mathrm{C}$ por 72 horas, aferindo-se a mass a com au xílio de balança analítica.

O delineamento experimental foi inteiramente casualizado, e as médias da altura da parte aérea, comprimento da raiz, massa seca da parte aérea, massa seca da raiz, razão massa seca da parte aérea e massa seca da raiz, número de nódulos e número de folhas foram comparadas pelo teste Tukey a 5\% de probabilidade.

\section{RES ULTADOS E DISCUSSÃO}

\section{Germinação}

Os resultados obtidos comparando-se as médias de germinação de sementes de M. brasiliense, sob fotoperíodo de $12 \mathrm{~h}$ e escuro contínuo, demonstraram que a ausência de luz não afetou a germinação, não sendo observada diferença significativa entre os tratamentos, independentemente da temperatura. $\mathrm{O}$ mes mo foi re latado em diversos trabalhos com espécies de Fabaceae. Mello e Barbedo (2007) verificaram não ocorrer interação entre luz e temperatura ou efeito isolado da luz e escuro contínuos para a germinação de Caesalpinia echinata Lam. Para sementes de Anadenanthera colubrina (Vell.) Brenam, a PG não foi afetada nem pelas condições de luz nem pela de escuro (VARELA; ALBORNOZ, 2013). O mesmo foi observado por Mondo et al. (2008), em que a presença ou ausência de luz não afetou o processo germinativo de sementes de Parapiptadenia rigida (Benth.) Brenan.

A temperatura exerce grande influência sobre a velocidade e porcentagem final de germinação (MARCOS FILHO, 2005). Em geral, a te mperatura é u m dos fatores de maior importância ambiental, regulando o tempo e a velocidade de germinação (ROJAS-ARÉCHIGA et al., 1998). Assim, considerando a germinação de sementes de $M$. brasiliense, independentemente da exposição ao fotoperíodo de $12 \mathrm{~h}$ e escuro contínuo, observou-se maior porcentagem de germinação (PG) para as sementes submetidas a 20 e $25^{\circ} \mathrm{C}$, o mesmo sendo verificado para o parâmetro índice de velocidade de germinação (IVG) (Tabela 1), enquanto a menor porcentagem de germinação foi observada para as sementes mantidas a $30{ }^{\circ} \mathrm{C}$.

Tabela 1. Porcentagem de germinação (PG), tempo médio de germinação (TMG) e índice de velocidade de germinação (IVG) de sementes de Machaerium brasiliense Vogel submetidas a diferentes temperaturas.

Table 1. Germination Percentage (PG), Average Germination Time (TMG), Germination Speed Index (IVG) of Machaerium brasiliense Vogel seeds subjected to different te mperatures.

\begin{tabular}{lccc}
\hline Tratamentos / Parâmetros & $\begin{array}{l}\text { PG } \\
(\boldsymbol{\%})\end{array}$ & $\begin{array}{c}\text { IVG } \\
\text { (sementes germinadas dia } \mathbf{~}^{\mathbf{1}} \text { ) }\end{array}$ & $\begin{array}{c}\text { TMG } \\
(\mathbf{d i a s})\end{array}$ \\
\hline $20^{\circ} \mathrm{C}$ & $60 \pm 9,89 * \mathrm{a}$ & $3,94 \pm 1,27 \mathrm{ab}$ & $6,12 \pm 0,76 \mathrm{a}$ \\
$25^{\circ} \mathrm{C}$ & $52 \pm 9,89 \mathrm{a}$ & $6,06 \pm 1,27 \mathrm{a}$ & $2,63 \pm 0,76 \mathrm{~b}$ \\
$30^{\circ} \mathrm{C}$ & $30 \pm 9,89 \mathrm{~b}$ & $2,14 \pm 1,27 \mathrm{~b}$ & $3,95 \pm 0,76 \mathrm{~b}$ \\
\hline
\end{tabular}

*Parâmetros seguidos por letras iguais não diferem pelo teste de Tukey a $5 \%$. Dados \pm desvio padrão.

As sementes germinaram entre dois e três dias quando mantidas a $25^{\circ} \mathrm{C}$, enquanto que a $20{ }^{\circ} \mathrm{C}$ apresentaram atraso na germinação (Tabela 1). Não se observou diferença significativa em relação ao tempo

FLOREST A, Curitiba, PR, v. 46, n. 1, p. 83 - 92, jan. / mar. 2016.

Pastorini, L. H. et al.

ISSN eletrônico 1982-4688

DOI: $10.5380 /$ rf.v46il .39625 
médio de germinação (TMG) para as sementes mantidas a 25 e $30^{\circ} \mathrm{C}$. Considerando o IVG, as sementes mantidas a $30^{\circ} \mathrm{C}$ apresentaram menor nú mero de sementes germinadas por dia, o que pode ser atribuído ao menor nú mero de sementes germinadas, com o término da germinação em quatro dias. Mello e Barbedo (2007) verificaram que, quanto mais elevada a temperatura para a germinação de sementes de Caesalpinia echinata (Fabaceae), mais concentrada temporalmente ela foi em torno do número médio de dias para germinar.

A manutenção das sementes de $M$. brasiliense sob $30^{\circ} \mathrm{C}$ pode ter ocasionado a morte das sementes, o que foi evidenciado pela redução significativa da porcentagem de germinação. A causa da morte de sementes por altas temperaturas pode ser atribuída à fluide z da me mbrana e quebra de proteínas, o que foi re latado por Eberle et al. (2014) e Rojas-Aréchiga et al. (1998). A inda, segundo Eberle et al. (2014), espécies reativas de oxigênio geralmente aumentam durante a embebição e provavelmente permaneçam em altas concentrações na semente, quando estas são mantidas em altas temperaturas, causando sua morte.

Assim, o melhor desempenho de germinação das sementes sob temperaturas entre 20 e $25^{\circ} \mathrm{C}$ está de acordo com as condições ambientais no período de maturação e dispersão das sementes de M. brasiliense.

Avaliação do crescimento inicial

Em relação aos parâmetros de crescimento, não se verificou diferença significativa entre os 180,270 e 360 DAT (Figura 1A). Aos 90 DAT, as plantas apresentaram, em média, 18,90 cm, sendo que aos 180 DAT houve incremento de 75\%, com as plantas apresentando cerca de $33 \mathrm{~cm}$ de altura. Já aos 270 e 360 DAT, foi observado que as plantas apresentaram aproximadamente 40 e $37 \mathrm{~cm}$ de altura, respectivamente. Apesar de se esperar aumento contínuo de altura ao longo do tempo, a variabilidade apresentada pelas plantas resultou em ausência de diferença significativa entre as últimas épocas de análise. Considerando o comprimento da raiz, também não se observou diferença significativa entre os dias após o transplante (Fig ura 1B).
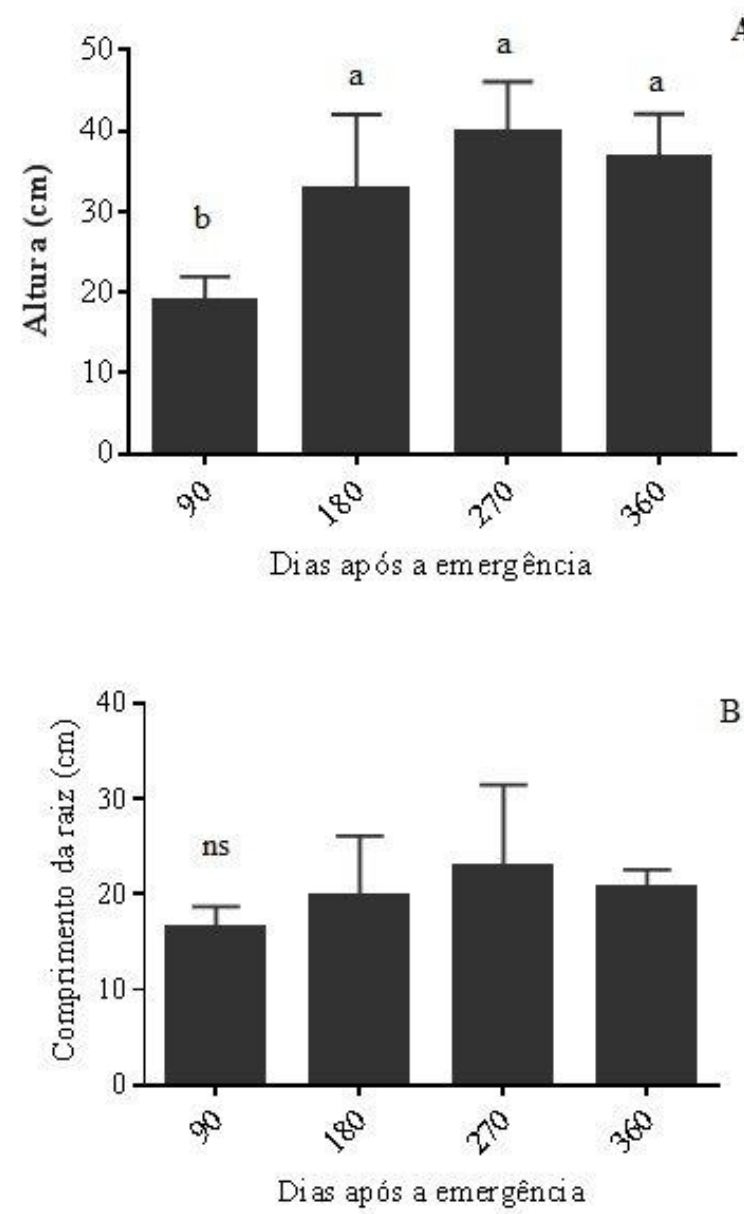

Figura 1. Altura da parte aérea (A) e comprimento da raiz (B) de plantas de Machaerium brasiliense Vogel aos 90, 180, 270 e 360 dias após o transplante (DAT). Letras iguais não diferem pelo teste de Tukey a 5\%.

Figure 1. Shoot height (A) and root length (B) of Machaerium brasiliense Vogel plants at 90, 180, 270 and 360 days after transplanting (DAT). The same letter do not differ by Tukey test at $5 \%$. 
Assim, considerando que no transplante das plântulas para os vasos elas apresentavam em média $6,42 \mathrm{~cm}$ de altura da parte aérea, $8,51 \mathrm{~cm}$ de comprimento da raiz e três folhas, houve aumento de $194 \%$ na altura da parte aérea, de $92,36 \%$ no comprimento da raiz e aumento de $200 \%$ no número de folhas, quando em comparação com as plantas avaliadas aos 90 DAT. Já aos 180 DAT, houve incremento de 72,59\% na altura da parte aérea e de $61,11 \%$ no número de folhas em relação aos 90 DAT.

A massa seca da parte aérea foi significativamente inferior aos 90 e 180 DAT em comparação aos 270 DAT, no entanto não se observou diferença significativa entre os 270 e 360 DAT (Figura 2 A). A massa seca da raiz foi superior aos 270 e 360 DAT e significativamente inferior aos 90 e 180 DAT (Figura 2B), sendo o mesmo observado para a massa seca total (Figura 3 ).
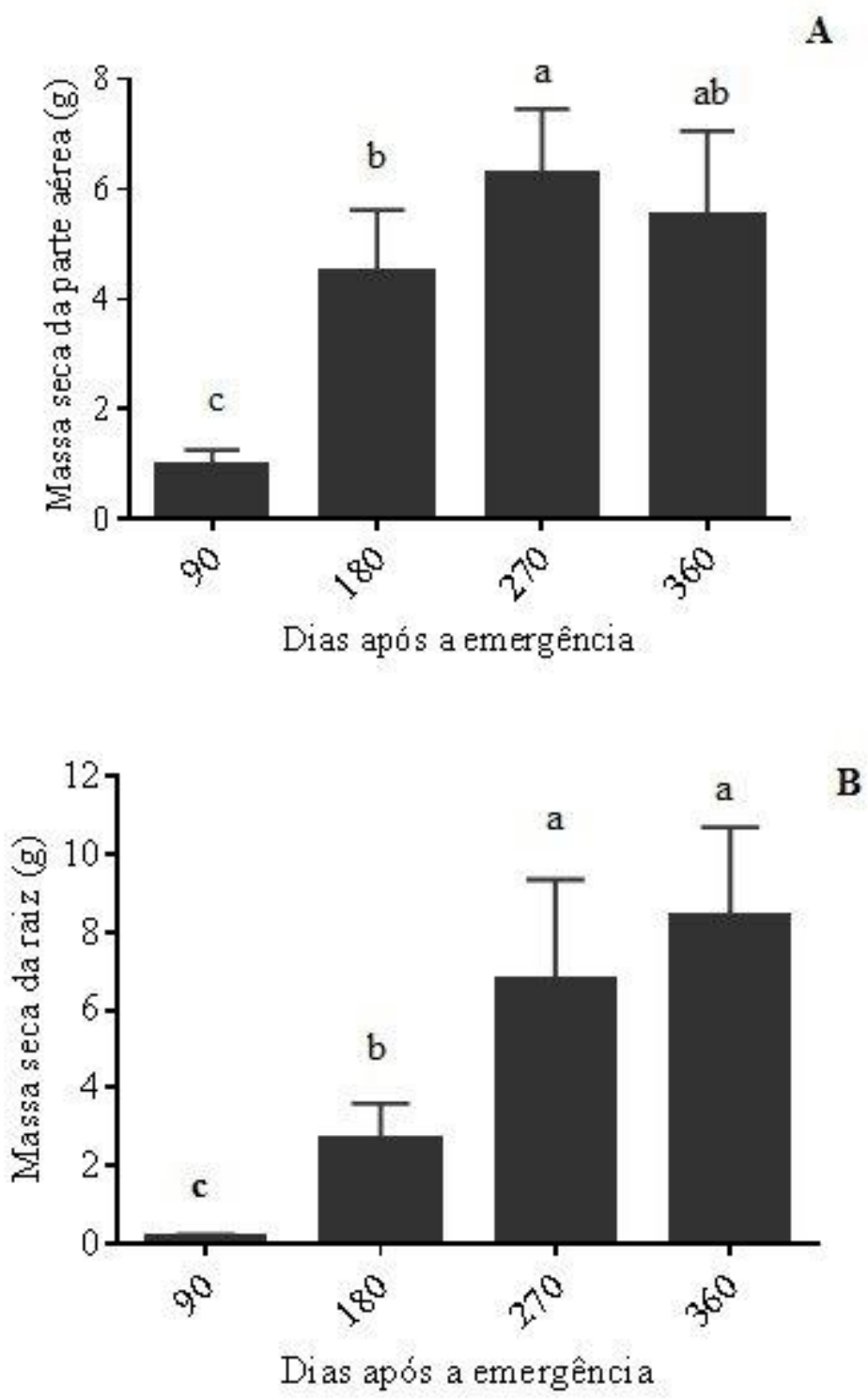

Figura 2. Massa seca da parte aérea (A), da raiz (B) de plantas de Machaerium brasiliense Vogel aos 90, 180, 270 e 360 dias após o transplante (DAT). Letras iguais não diferem pelo teste de Tukey a 5\%.

Figure 2. Shoot dry mass (A), root (B) of Machaerium brasiliense Vogel plants at 90, 180, 270 and 360 days after transplanting (DAT). The same letter do not differ by Tukey test at $5 \%$.

Comparando os dados obtidos para M. brasiliense com estudos realizados com Parapiptadenia rigida, que é uma es pécie considerada pioneira e de rápido crescimento, foi verificado por Schu macher et al. (2004) que plantas de $P$. rigida com 130 dias e $20 \mathrm{~cm}$ de altura da parte aérea apresentaram massa seca da raiz de $0,6 \mathrm{~g}$ e massa seca total de $1,3 \mathrm{~g}$, sendo esses valores inferiores aos obtidos no presente trabalho para M. brasiliense.

FLOREST A, Curitiba, PR, v. 46, n. 1, p. 83 - 92, jan. / mar. 2016.

Pastorini, L. H. et al.

ISSN eletrônico 1982-4688

DOI: $10.5380 /$ rf.v46il .39625 


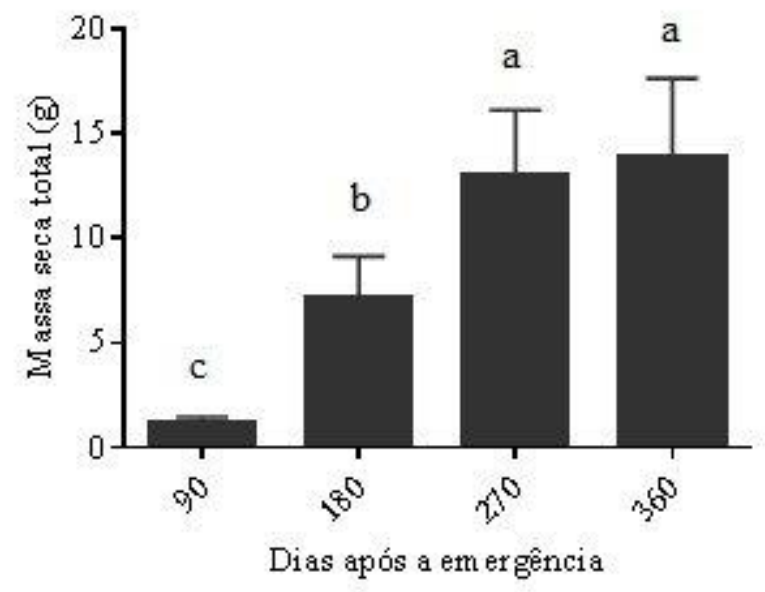

Figura 3. Massa seca total de plantas de Machaerium brasiliense Vogel aos 90, 180, 270 e 360 dias após o transplante (DAT). Letras iguais não diferem pelo teste Tukey a 5\%.

Figure 3. Total dry mass of de Machaerium brasiliense Vogel plants at 90, 180, 270 and 360 days after transplanting (DAT). The same letter do not differ by Tukey test at $5 \%$.

A ausência de diferença em relação aos parâmetros de crescimento (altura e comprimento da raiz) de M. brasiliense aos 180, 270 e 360 DAT (Figura 1 A e B) e em relação aos parâmetros (massa seca da parte aérea, massa seca da raiz e massa seca total) aos 270 e 360 DAT (Figura 2 A e B e Figura 3) pode ser atribuída à lenta taxa de crescimento da espécie.

O nú mero de folhas foi superior aos 360 DAT, não diferindo aos 180 e 270 DAT (Figura 4). Ferreira et al. (2012) observaram que plantas de Anadenanthera colubrina apresentaram 9 folhas aos 90 dias, sendo o mes mo observado no presente trabalho para M. brasilisense aos 90 DAT. No entanto, aos 180 DAT, as plantas de $M$. brasiliense apresentaram em média 15 folhas, sendo superior ao observado para A. colubrina, com 10 folhas aos 180 dias.

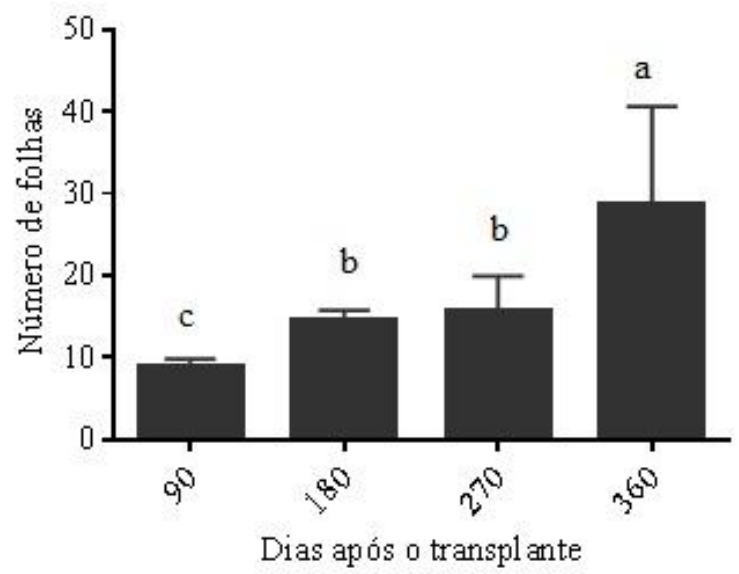

Figura 4. Número de folhas de plantas de Machaerium brasiliense Vogel aos 90, 180, 270 e 360 dias após o transplante (DAT). Letras iguais não diferem pelo teste de Tukey a $5 \%$.

Figure 4. Number of leaves plant Machaerium brasiliense Vogel at 90, 180, 270 and 360 days after transplanting (DAT). The same letter do not differ by Tukey test at $5 \%$.

Em relação à razão massa seca da parte aérea/massa seca da raiz (MSPA/MSR), aos 90 DAT houve maior investimento na PA, com maior MSPA/MSR nesse período (Figura 5). A partir dos 180 DAT, ocorreu redução da razão MSPA/MSR, o que pode ser associado ao incremento da massa seca da raiz no período

FLOREST A, Curitiba, PR, v. 46, n. 1, p. 83 - 92, jan. / mar. 2016. Pastorini, L. H. et al. 
(Figura 5 e Figura 2B). De acordo com Ferreira et al. (2012), maior razão MSPA/MSR é resultado de maior investimento de biomassa para as raízes, possibilitando maior absorção de água para suprir a demanda transpiratória, o que pode ser relacionado ao maior número de folhas verificado a partir dos 180 DAT (Figura 4). O aumento da razão MSPA/MSR pode também estar vinculado ao crescimento lento da espécie, o que foi observado por Ferreira et al. (2012) em estudo com plantas de A. colubrina.

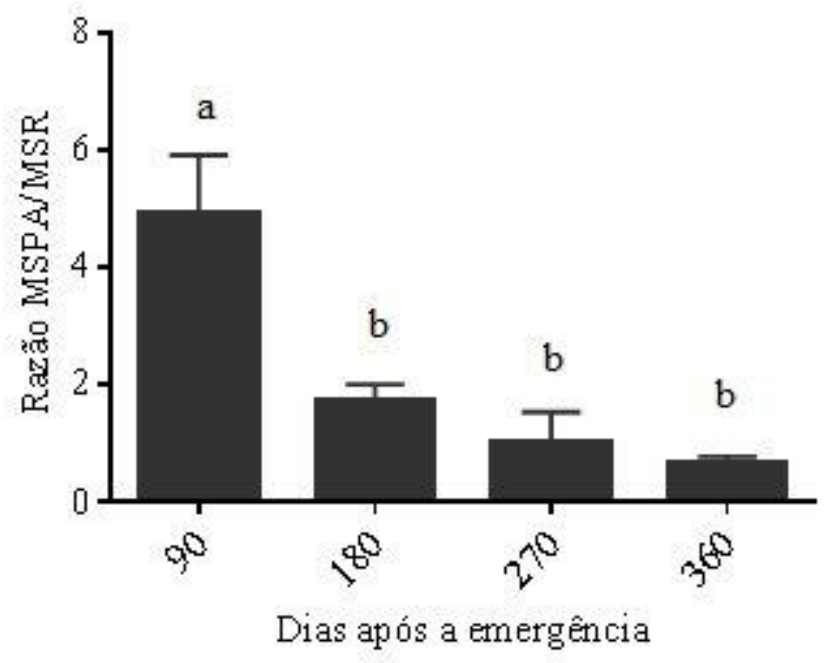

Figura 5. Razão massa seca da parte aérea e massa seca da raiz de plantas de Machaerium brasiliense Vogel aos 90, 180, 270 e 360 dias após o transplante (DAT). Letras iguais não diferem pelo teste de Tukey a $5 \%$.

Figure 5. Ratio dry mass of shoot and root dry mass of plants Machaerium brasiliense Vogel at 90, 180, 270 and 360 days after transplanting (DAT). The same letter do not differ by Tukey test at $5 \%$.

Considerando os parâmetros de crescimento, a MSPA indica a rusticidade das mudas, sendo que, quanto maior o valor, maior lignificação e maior sucesso no estabelecimento em condições advers as (GOMES; PAIVA, 2006), o que para $M$. brasiliense foi observado a partir dos 270 DAT. Nesse período também se observaram os maiores valores para a MSR e MST, que garantiria maior qualidade às mudas e possibilidade de maior sucesso no estabelecimento em campo.

A presença de nódulos foi observada somente a partir dos 180 DAT, sendo que o número de nódulos não variou significativamente durante as demais épocas de coleta (Figura 6). A nodulação ocorreu espontaneamente, considerando que não houve nenhum procedimento de ino culação para o presente estudo.

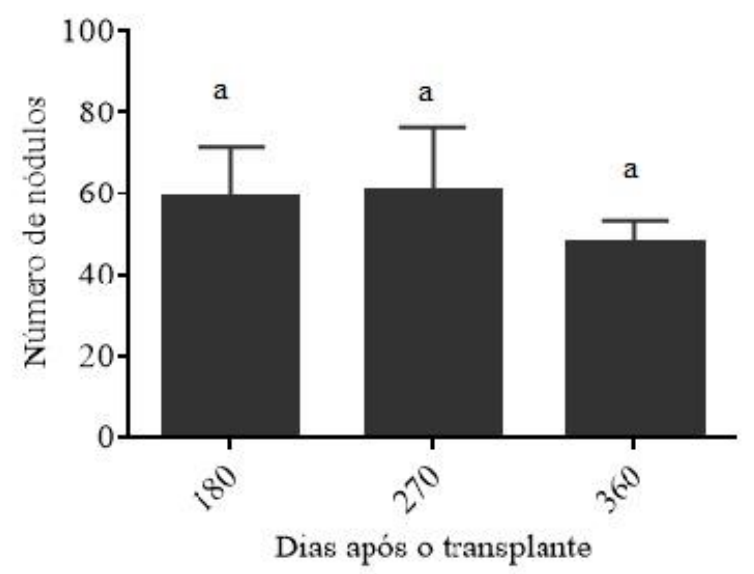

Figura 6. Número de nódulos em plantas de Machaerium brasiliense Vogel aos 180, 270 e 360 dias após o transplante (DAT). Letras iguais não diferem pelo teste de Tukey a 5\%.

Figure 6. Number of nodules in Machaerium brasiliense Vogel plants at 90, 180, 270 and 360 days after transplanting (DAT). The same letter do not differ by Tukey test at $5 \%$. 
Uma das características das Fabaceae é a capacidade de nodulação radicular, sendo que para grande parte das espécies arbóreas nativas ainda faltam informações a respeito da capacidade de nodulação. Faria et al. (1984) observaram a presença de nódulos espontâneos (sem inoculação) em plantas jovens de espécies de Machaerium, presentes no campo (em reserva florestal) e em viveiros.

Oliveira (2001) verificou a presença de nódulos aos 240 dias de crescimento em plantas jovens de Sophora tomentosa L., aos 390 dias para Swartzia langsdorffii Raddi. e aos 180 dias para Lonchocarpus muehlbergianus Hassl. A autora também observou que a raiz principal dessas plantas era espessa, o que também foi encontrado para M. brasiliense no presente estudo (Figura 7).

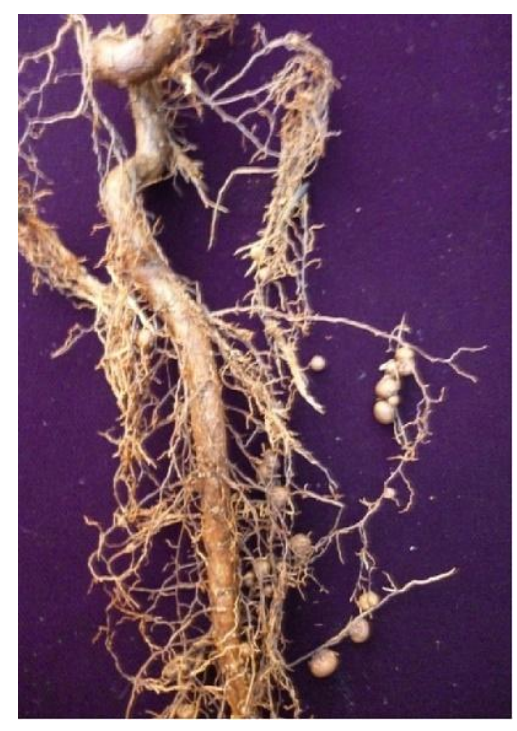

Figura 7. Raiz de Machaerium brasiliense, apresentando nódulos nas raízes laterais aos 180 DAT.

Figure 7. Machaerium brasiliense root, with nodules on the lateral roots to 180 DAT.

Quanto à morfologia, os nódulos encontrados em M. brasiliense são globosos e presentes somente nas raízes laterais (Figura 6), o que também foi observado por Faria et al. (1984) para nódulos em espécies de Machaerium e por Oliveira (2001) para outras espécies de leguminosas noduladas.

Remmler et al. (2014) re lata que a loca lização do nódulo não é aleatória. A zona da raiz onde irá ocorrer a formação do nódulo é a mais susceptível à infecção rizobial, permitindo a penetração do Rhizobium através do fio de infecção. Considerando que $M$. brasiliense apresenta a raiz principal espessa e lenhificada (Figura 7), o aparecimento de nódulos somente nas raízes laterais estaria as sociado à facilitação da penetração do Rhizobium, dando início à formação do nódulo. Além disso, uma sinalização hormonal é necess ária para a nodulação e formação da raiz lateral. A auxina é necessária para estimular a divisão celular no periciclo, levando ao desenvolvimento da raiz lateral, o que simultaneamente tem sido demonstrado para o desenvolvimento dos nódulos, resultantes da as sociação simbiótica (WASSON et al., 2009).

Djordjevic et al. (2015) relatam que as raízes laterais são os principais órgãos para a aquisição de nutrientes, no entanto, como as leguminosas coordenam a formação dos nódulos nas raízes laterais ainda não é totalmente co mpreendido, sendo que estudos recentes indicam a sinalização de peptídeos na regulação sis têmica da formação do nódulo e da raiz lateral.

\section{CONCLUS ÕES}

- A maior porcentagem de germinação (PG) observada para as sementes submetidas a 20 e $25{ }^{\circ} \mathrm{C}$ pode estar relacionada com os valores de temperatura dos meses em que os frutos e sementes amadurecem nas Florestas Estacionais Semideciduais, formações fitoecológicas nas quais M. brasiliense tem ocorrência natural e elevado valor de importância.

- A semelhança dos resultados da germinação nos diferentes fotoperíodos (fotoperíodo $12 \mathrm{~h}$ e escuro) indica que $M$. brasiliense apresenta potencial para restauração tanto de áreas relativamente abertas quanto em mais avançadas, que necessitem de enriquecimento de espécies. 
- A presença de nódulos foi observada a partir dos 180 DAT, e a maior altura, MSPA, MSR e MST a partir dos 270 DAT, o que permite sugerir maior qualidade das mudas a partir dos 270 DAT.

\section{REFERÊNCIAS}

ANDRADE, A. G.; TA VARES, S. R. L.; COUTINHO, H. L. C. Contribuição da serapilheira para recuperação de áreas degradadas e para manutenção da sustentabilidade de sistemas agroecológicos. Informe Agropecuário, v. 24, n. 220, p. $55-63,2003$.

ANDRADE, A. L. P.; MIOTTO, S. T. S.; SANTOS, E. P. A subfamília Faboideae (Fabaceae Lindl.) no Parque Estadual do Guartelá, Paraná, Brasil. Hoehnea, São Paulo, v. 36, n. 4, p. 737 - 768, 2009.

ARAúJO, L. H. B.; NÓBreGA, C. C.; SIllVA, R. A. R.; GUERRA, C. A. G.; SANTANA, J. A. S. Comportamento de mudas de es pécies florestais em projeto de restauração ecológica sobre área de dunas em Natal, RN. Agropecuária Científica no Semiárido, Patos, v. 10, n. 1, p. 122 - 127, 2014.

BENINCASA, M. M. P. Análise de crescimento de plantas. Jaboticabal: FUNEP, 1988. 42 p.

BRASIL. Instruções para análise de sementes de espécies florestais, Brasília: MAPA/DAS/CGA L, 2013. 98 p.

DJORDJEVIC, M. A.; MOHD-RADZMAN, N.; IMIN, N. Small-peptide signals that control root nodule number, development and symbiosis. Journal of Experimental Botany. v. 66, n. 17, p. 5171 - 5181, 2015.

EBERLE, C. A.; FORCELLA, F.; GESCH, R.; PETERSON, D.; EKLUND, J. Seed germination of calendula in response to temperature. Industrial crops and products, Philadelphia. 52: 199 - 204, 2014.

FARIA, S. M.; FRANCO, A. A.; MENANDRO, M. S.; JESUS, R. M.; BAITELL, J. B.; AGUIAR, O. T.; DÔBEREINER, J. Levantamento da nodulação de leguminosas florestais nativas na região Sudeste do Brasil. Pesquisa Agropecuária Brasileira, Brasília, v. 19, p. 143 - 153, 1984.

FERREIRA, A. G.; BORGHETTI, F. Germinação: do básico ao aplicado. Porto Alegre: Artmed, 2004. 323 p.

FERREIRA, W. N.; ZANDA VALLI, R. B.; BEZERRA, A. M. E.; MEDEIROS FILHO, S. Crescimento inicial de Piptadenia stipulacea (Benth.) Ducke (Mimosaceae) e Anadenanthera colubrina (Vell.) Brenan var. cebil (Griseb.) Altshul (Mimosaceae) sob diferentes níveis de sombreamento. Acta Botânica Brasílica, Brasília, v. 26, n. 2, $408-414,2012$.

FILA RDI, F. L. R.; LIMA, H. C. The diversity of Machaerium (Leguminosae: Papilionoideae) in the Atlantic Forest: three new species. Systematic B otany, Washington, v. 39, n. 1 p. 145 - 160, 2014.

GOMES, J. M.; PAIVA, H. P. Vi veiros florestais (propagação sexuada). Viçosa, MG: Universidade Federal de Viçosa, 2006. 116 p. (Caderno Didático, 72).

GUIMARÃES, D. M.; BARBOSA, J. M. Coloração dos frutos como índice de maturação para sementes de Machaerium brasiliense Vogel (Leguminosae - Fabaceae). Revista Brasileira de Biociências, Porto Alegre, v. 5, supl. 2, p. 567 - 569, 2007.

INSTITUTO A GRONÔMICO DO PARANÁ (IAPAR). 2012. Cartas Climáticas do Paraná. Disponível <http://www.iapar.br/modules/conteudo/conteudo.php?conteudo=677>. Acesso em: nov. 2012.

INSTITUTO BRASILEIRO DE GEOGRAFIA E ESTATÍSTICA (IBGE). Manual técnico da vegetação brasileira: Série Manuais Técnicos em Geociências. Rio de Janeiro: IBGE. 2012. 470 p.

LIMA, J. D.; SILVA, B. M. S.; MORAES, W. S.; DANTAS, V. A. V.; ALMEIDA, C. C. Efeitos da luminosidade no crescimento de mudas de Caesalpinia ferrea Mart. ex Tul. (Leguminosae, Caesalpinoideae). Acta Amazonica, Manaus, v. 38, n. 1, p. 5 - 10, 2008.

LORENZI, H. Árvores Brasileiras: manual de identificação e cultivo de plantas arbóreas nativas do Brasil. Vol. 2. 4. ed. Nova Odessa, SP: Editora Plantarum. 2014.

MAGUIRE, J. D. Speed of germination-aid in selection and evaluation for seedling emergence and vigor. Crop Science, Madison, v. 2, n. 1, p. 176 - 177, 1962.

MARCOS FILHO, J. Fisiologia de sementes de plantas cultivadas. Piracicaba: FEALQ, 2005. 495 p.

MELLO, J. I. O.; BARBEDO, C. J. Temperatura, luz e substrato para germinação de sementes de pau-brasil

FLOREST A, Curitiba, PR, v. 46, n. 1, p. 83 - 92, jan. / mar. 2016.

Pastorini, L. H. et al.

ISSN eletrônico 1982-4688

DOI: 10.5380/rf.v46il .39625 
(Caesalpinia echinata Lam., Leguminosae - Caesalpinioideae). Revista Árvore, Viçosa, v. 31, n. 4, p. 645 655, 2007.

MONDO, V. H. V.; BRANCALION, P. H. S.; CICERO, S. M.; NOVEMBRE, A. D. L. C.; DOURADO NETO, D. Teste de germinação de sementes de Parapiptadenia rigida (Benth.) Brenan (Fabaceae). Re vista Brasileira de Sementes, Londrina, v. 30, n. 2, p. 177 - 183, 2008.

MOTA, L. S.; GARCIA, Q. S. Germination patterns and ecological characteristics of Vellozia seeds from highaltitude sites in south-eastern Brazil. Seed Science Research, Cambridge, v. 23, p. 67-74, 2013. Doi:10.1017/S0960258512000256.

OLIVEIRA, D. M. T. Morfologia comparada de plântulas e plantas jovens de leguminosas arbóreas nativas: espécies de Phaseoleae, Sophoreae, Swart zieae e Tephrosieae. Revista Brasileira de Botânica, São Paulo, v. 24, n. 1, p. $85-97,2001$.

OLIVEIRA, A. K. M.; RIBEIRO, J. W. F.; PEREIRA, K. C. L.; SILVA, C. A. A. Effects of temperature on the germination of Diptychandra aurantiaca (Fabaceae) seeds. Acta Scientiarum. Agronomy, Maringá, v. 35, n. 2, p. 203-208, 2013. Doi: 10.4025/actasciagron.v.35i2.15977.

OROZCO-SEGOVIA, A.; VÁZQUEZ-YANES， C.; COATES-ESTRADA， R.; PÉREZ-NASSER, N. Ecophysiological characteristics of the seed of the tropical forest pioneer Urera caracasana (Urticaceae). Tree Physiology, Victoria, v. 3, p. 375 - 386, 1987.

PINZÓN-TORRES, J. A.; SCHIA VINATO, M. A. Crescimento, eficiência fotossintética e eficiência do uso da água em quatro espécies de leguminosas arbóreas tropicais. Hoehnea, São Pau lo, v. 35, n. 3, p. 395 - 404, 2008.

RAMAKRISHNAN, P. S.; SHUKLA, R. P.; BOOJH, R. Growth strategies of trees and their application to forest management. Current Science, v. 51, p. 448 - 455, 1982.

REMMLER, L.; CLAIRMONT, L.; ROLLAND-LAGAN, A-G.; GUINEL, F. C. Standardized mapping of nodulation patterns in legume roots. New Phytologist, v. 202, p. 1083 - 1094, 2014.

RODRIGUES, A. C. C. R.; OSUNA, J. T. A.; QUEIROZ, S. R. O. D.; RIOS, A. P. A. Efeito do substrato e lu minosidade na germinação de Anadenanthera colubrina (Fabaceae, Mimosoideae). Revista Árvore, Viçosa, v. 31, n. 2, p. 187 - 193, 2007.

ROJAS-ARÉCHIGA, M.; VÁZQUEZ-YANES, C.; OROZCO-SEGOVIA, A. Seed response to temperature of Mexican cacti species from two life forms: an ecophysiological interpretation. Plant Ecology, v. 135, n. 2, p. $207-214,1998$.

SCHUMACHER, M. V.; CECONI, D. E.; SANTANA, C. A. Influência de diferentes doses de fósforo no crescimento de mudas de angico-vermelho (Parapiptadenia rigida (Bentham) Brenan). Revista Árvore, v. 28, n. 1 , p. 149 - 155, 2004.

SILVA, K. A.; MARTINS, S. V.; MIRANDA NETO, A.; CAMPOS, W. H. Se meadura direta com transposição de serapilheira co mo metodologia de restauração ecológica. Revista Árvore, v. 39, n. 5, p. 811 - 820, 2015.

SOCOLOWSK, F.; TAKAKI, M. Germinação de sementes e emergência de plântulas de Tabebuia rosea (Bertoloni) a.p. De Candolle (Bignoniaceae), uma espécie exótica com potencial invasor. Revista Árvore, Viçosa, v. 31, n. 2, p. 229 - 238, 2007.

VARELA, R. O.; ALBORNOZ, P. L. Morpho-anatomy, imbibition, viability and germination of the seed of Anadenanthera colubrina var. cebil (Fabaceae). Revista Biología Tropical, San José, v. 61, n. 3, p. 1109 - 1118 , 2013.

VINI, R. A. G.; RODRIGUES, G. R. Sobrevivência em viveiro de mudas de espécies nativas retiradas de regeneração natural de remanescente florestal. Pesquisa Agropecuária Brasileira, v. 42, n. 8, p. 1067 - 1075, 2007.

YANG, Q-H.; WEI, X.; ZENG, Z-L.; YE, W-H.; YIN, X-J.; ZHANG-MING, W.; JIANG, Y-S. Seed biology and germination ecophysiology of Camellia nitidissima. Forest Ecology and Management, Amsterdan, v. 255, p. $113-118,2008$.

WASSON, A-P.; RAMSA Y, K.; JONES, M. G. K.; MATHESIUS, U. Differing requirements for flavonoids during the formation of lateral roots, nodules and root snot nematodes galls in Medicago truncatula. New Phytol ogist, v. 183, p. 167 - 179, 2009. 